\title{
Assembling Upstream Engagement: the Case of the Portuguese Deliberative Forum on Nanotechnologies
}

\author{
António Carvalho ${ }^{1,2}$ \& João Arriscado Nunes ${ }^{2}$ \\ 1) Institute of Hygiene and Tropical Medicine, NOVA University of Lisbon, Lisbon, Portugal. \\ 2) Centre for Social Studies, University of Coimbra, Coimbra, Portugal.
}

\begin{abstract}
This article analyzes a deliberative forum on nanotechnologies, organized in Portugal within the scope of the research project DEEPEN-Deepening Ethical Engagement and Participation in Emerging Nanotechnologies. This event included scientists, science communicators and members of the "lay public", and resulted in a position document which summarizes collective aspirations and concerns related to nano. Drawing upon our previous experience with focus groups on nanotechnologies - characterized by methodological innovations that aimed at suspending epistemological inequalities between participants - this paper delves into the performativity of the deliberative event, exploring some of the tensions and power/knowledge asymmetries generated by the forum. Recognizing that the design of participatory assemblages matters, we reflect on our role as facilitators and explore the difficulties in organizing exercises of upstream engagement with emerging technologies.
\end{abstract}

Keywords: Deliberation; Upstream engagement with nanotechnologies; Responsible research and innovation; Performativity

\section{Introduction}

This paper offers a reflection on a deliberative forum organized in Portugal within the scope of the EC-funded project DEEPEN (Deepening Ethical Engagement and Participation in Emerging Nanotechnologies) in 2009 at the Centre for Social Studies of the University of Coimbra. The development of nanotechnologies has been considered an opportunity to develop upstream forms of public participation which will ideally allow the public to engage with $R \& D$ processes while these take place $[25,32,33]$

Upstream engagement has been proposed as an antidote to ad hoc forms of participation which increase the gap between science and society-what Callon, Lascoumes and Barthe [9] characterized as double delegation. According to them, double delegation refers to the process whereby citizens delegate, through electoral or administrative mechanisms, the authority to deal with political or administrative issues on elected officials and civil servants, and the authority to deal with scientific or technical issues on duly certified experts. In the case of GMOs, double delegation and the lack of public participation triggered a severe public backlash with considerable economic costs [28].

The DEEPEN project was at the forefront of this upstream approach to public participation and engagement with nanotechnologies. Initially, focus groups were organized in Portugal and the UK, aiming at identifying the ethicalities of these emerging technologies [11, 31]. The focus 
groups followed the call for the use of innovative forms of participative methodologies with nano [36], and both the Portuguese and British teams transformed the classical model of focus groups through the inclusion of engaged approaches-Paulo Freire's Pedagogy of the Oppressed [21] and Augusto Boal's Theater of the Oppressed [5] — which contrasted with more traditional forms of deliberation exclusively focused on the rational argument.

However, the focus groups were merely consultative- they allowed us to identify the main social and ethical concerns with nano, which were understood, according to the British team, as underpinning five main cultural narratives: Be Careful What You Wish for; Pandora's Box; Messing with Nature; Kept in the Dark; The Rich Get Richer [13].

However, and in order to reinforce the upstream dimension of this research project, a deliberative forum was organized to allow members of the lay public - along with scientists involved in nanotechnology research and science communicators - to formulate a set of recommendations which would ideally inform R\&D processes.

The emergence of forms of public participation with science and technology (S\&T) - including nanotechnologies - has generated some concerns and words of caution within science and technology studies and social sciences in general (see the "Public Participation, Upstream Engagement, and the Challenges of New and Emerging Sciences and Technologies" section for some critical remarks on "upstream engagement"). Hamlet and Cobb [24], for instance, suggest that public deliberation on S\&T may trigger "decision-making pathologies," including polarization cascades: "individuals holding the minority opinion in a group adopt the majority opinion for normatively undesirable reasons after deliberating.” ([24], p. 631).

Social scientists and ethicists have recognized that aspects such as the style of moderation; group composition; the materials and environments participants are exposed to; epistemic, cultural, and social differences between participants; their stakes in the debate; and their willingness to participate strongly influence the outcome of public deliberation exercises [31].

Devices of public engagement are performative, and statements, recommendations, and "lay ethics" in general are deeply entwined with the participatory context/format. Participatory devices, in that sense, are understood as mediators that can bring forward certain ways of thinking about technologies, resembling Foucault's technologies of the self [20] and indicating that ethics and technologies are profoundly entangled and should not be understood as separate dimensions [43].

Through systematic comparisons with the previously organized focus groups, we explore how the context/format of the deliberative assemblage mattered, focusing specifically on the asymmetries between scientists/science communicators and members of the "lay public," reflecting on our role as facilitators, thus highlighting the performativity of the deliberative forum.

Following this introduction, the "Deliberation and Public Participation in Context" section of this paper introduces the reader to wider debates on deliberation and public participation. The "Public Participation, Upstream Engagement, and the Challenges of New and Emerging Sciences and Technologies" section traces the emergence and multiple facets of public participation on issues related to S\&T over the past few decades, and delves into the challenges posed by nanotechnologies regarding current concerns with public engagement with science, exploring some of the virtues and pitfalls of upstream forms of participation. The "Deliberative Forum on Nanotechnologies" section presents empirical data stemming from the deliberative forum organized in Coimbra. It is centered on the organization, methodology, discussions, recommendations, and reactions linked to this event. The "Discussion" section explores the performativity of the deliberative forum, analyzing aspects related to the selection of participants, group composition, and the role of social scientists as facilitators. 


\section{Deliberation and Public Participation in Context}

Deliberative exercises such as consensus conferences or citizen conferences, citizen juries, citizen panels, foresight exercises, scenario workshops and others [36, 37, 38] were innovative experiments with deliberative fora which became part of the repertoire of policy actors, and in particular of social democratic governments across Europe at the end of the last century. During the 1990s, those procedures were developed around controversial and potentially hazardous developments in scientific research, technology, and public policies [40]. These initiatives were usually launched in a top-down way by institutions associated with governments and/or parliaments or a range of State agencies. Some of these initiatives were institutionalized, thus becoming part of the normal workings of the State and of governance, as in Denmark [26].

Dryzek defines deliberation as a social process where "deliberators are amenable to changing their judgments, preferences, and views during the course of their interactions, which involve persuasion rather than coercion, manipulation, or deception" ([15], p. 1). Deliberation is thus seen as an attempt to strengthen democracy, fostering a type of democratic control that "is substantive rather than symbolic, and engaged by competent citizens" ([15], p.1).

A frequent mistake is to identify deliberation with consensus building or, at least, with the desirability of consensus. In fact, the most common output of deliberation seems to be more of a workable agreement, or composition [9], rather than consensus building, whereby composition participants agree on outcome, but not necessarily on reasons for the agreement.

The last two decades have witnessed a growing interest, within political theory, in deliberation and deliberative democracy. This trend was paralleled by a proliferation of experiments with deliberative spaces and fora both in liberal democracies of the Northern hemisphere and as a constitutive part of recent processes of (re)democratization in the South. Among political theorists, there was even talk of a deliberative turn [22] which has allegedly contributed to the reorientation of debate and research on democratic theory and practices.

Regarding sociotechnical issues, Fiorino identified three main arguments against the technocratic orientation which dictates that elites should be exclusively in charge of tackling risk problems: the substantive argument - "lay judgments about risk are as sound or more so than those of experts" ([16], p. 227); the normative argument - "a technocratic orientation is incompatible with democratic ideals" ([16]), p. 227); and the instrumental one- "effective lay participation in risk decisions makes them more legitimate and leads to better results" ([16], p. 228).

One of the main limitations of participatory procedures, often underlined by their critics, is the lack of effectiveness of these procedures to actually influence decision-making in a significant way. The lack of binding power of deliberations in most of these initiatives prevents or limits the empowerment of participants, understood as the capacity to have any degree of effective control over decisions [2]. As we will see in the following section, recently there has been a trend toward upstream forms of public engagement with science and technology, allowing citizens to interact with scientists, stakeholders, and policy makers, with a potential impact on the development of innovative applications such as nanotechnologies.

\section{Public Participation, Upstream Engagement and the Challenges of New and Emerging Sciences and Technologies}

A rough and provisional attempt at classifying participatory procedures in science and technology which rely on deliberation would yield three main types [36, 37, 38]: 
- Participatory technology assessment, including consensus conferences or citizen conferences, citizen juries and citizen panels, and other, ad hoc or institutionalized forms of deliberative fora;

- Foresight exercises and scenario workshops. Although they are not always explicitly designed as deliberative, deliberation may be a central process in these exercises;

- Participatory technology development and participatory policy design, including constructive technology assessment, initiatives aiming at the development of appropriate technologies or exercises in urban planning and design of public policies, including participatory planning and participatory budgeting.

These devices of public dialog and engagement with S\&T differ in terms of context, scope and design, delivery, impact, and evaluation [(39, p. 10-25)]. Most of the initiatives found in Europe would fall within the class of consultative (versus binding) procedures. Decision-making is still the province of political officials, administration and experts, even if informed by citizen participation. Some of these initiatives were institutionalized, thus becoming, in some countries, part of the normal workings of the State and of governance [34]. They seem to have contributed, in some cases at least, to the production of more robust knowledge on controversial issues, namely on those with potential adverse effects on human populations and the environment, and they certainly were used by the promoting or sponsoring bodies to increase the legitimacy of public policies, especially where these were contested or likely to be contested. Some of the controversial issues associated with developments in the life and biomedical sciences and in emerging technologies, including nanotechnologies, seem to have found in deliberative fora spaces for informed and rational discussion under the conditions of axiological pluralism which are characteristic of contemporary societies [12,27].

New and emerging sciences and technologies (NESTs), such as nanotechnologies, synthetic biology, and geoengineering [3], raise novel challenges to existing deliberative procedures as they are used to engage citizens in public debate. Unlike the procedures associated with participatory technology assessment, participants in debates over emerging sciences and technologies such as nanosciences and nanotechnologies are faced with knowledge and technologies in the making, which cannot be assessed on the basis of their actual consequences for society, environment, or health or for their effects on specific groups or collectives [6]. The framing of fora as debates on ethical issues is frequent, and their main contribution is to provide upstream assessments of possible future developments of research and of technologies.

According to Flynn et al., devices of upstream engagement with science and technology contrast with the traditional model of public understanding of science, turning citizens into active agents with the ability to influence R\&D:

Upstream' deliberative engagement implies an active role for citizens throughout the entire process of scientific research and development. In this process, citizens are not merely passive recipients of an established body of expert knowledge which nullifies their contribution to decisions about the desirability or feasibility of a technology. ([17], p. 245).

However, and despite the apparent virtues of upstream engagement, the authors highlight three major limitations: the fact that the available information might be too complex/technical, thus undermining the ability of citizens to systematically assess the advantages and/or disadvantages of certain technologies; the difficulty to pinpoint who should be involved in engagement exercises, due to the difficulties in identifying who will most likely be affected by certain innovations (as we will see in "The Deliberative Forum on Nanotechnologies" section, this was an issue we came across while organizing the forum); although governments and stakeholders 
may foster the acceptance of an emerging technology, exercises of upstream engagement might result in the rejection or a limited/conditional approval of a specific innovation ([17]), p. 246).

Wilsdon et al. also suggest that "Upstream engagement is no panacea" ([45], p. 52). According to them, upstream engagement may allow the debate to move away from "models of prediction and control," bringing forward a "richer public discussion about the visions, ends and purposes of science" ([45], p. 34). However, the authors are critical of the metaphor of linearity, arguing that innovation does not take place in a linear fashion but rather relies on "networks of interaction between inventors, scientists, engineers, users and business people" ([45], p. 36).

The metaphor of linearity, when applied to "upstream engagement," is also questioned, as it assumes that it is possible to "add" public engagement at crucial stages of innovation processes. Instead, the authors suggest that the linear model should be abandoned, allowing exercises of upstream engagement to be disseminated throughout innovation processes, leading to stronger science/society couplings:

upstream engagement-at a point where research trajectories are still open and undetermined - should be the start of a process of ongoing deliberation and social assessment, that embeds dialogue between scientists, stakeholders and lay publics within all stages of the R\&D process. ([45], p. 38)

Regarding nanotechnologies, Swierstra and Rip argue that "most ethical questions presently raised about nanotechnology belong to NEST-ethics" ([41], p. 4) and that "while there may not be a nano-ethics, there definitely is a NEST-ethics." ([41], p. 4), although nanotechnologies "introduce some specific questions for NEST-ethics, and makes existing questions/issues more urgent" ([41], p. 18).

The authors also develop important insights on deliberative devices, arguing that, in the case of nanotechnologies, exercises aimed toward consensus will not work due to the ambivalent characteristics of nanotechnologies - as Swierstra and Rip suggest, "Nanotechnology introduces new ambivalencies, and enhances existing ones." ([41], p. 16).

Therefore, and due to the challenging characteristics of nano, participatory devices also need to be adjusted, as ethics and technologies (including technologies of public participation) are coproduced. In that sense, the authors suggest that the classical Athenian Agora - often presented as the ideal model for deliberation, based on the strongest argument - should be replaced by the Arena, where particular group interests play a predominant role:

Not an agora where Rousseau's volonté generale takes form, but an arena where some win and others lose. In an arena consensus is never reached, although a workable compromise is sometimes achieved. Consensus-seeking models can at best provide temporary stabilisations. ([41], p. 18)

As we will see in "The Deliberative Forum on Nanotechnologies" section, this insight is particularly well aligned with the Portuguese deliberative experiences with nano, where specific group interests inevitably triggered particular ethical and social concerns, both during the focus groups and the deliberative forum, requiring a workable compromise to reach a "closure." This also raises another issue, which has to do with the habilitation of participants - in fact, it would be utopian to believe that the perfect participative method would lead to the equal habilitation of citizens.

According to Blok and Lemmens, there are various factors that can hinder current attempts to carry out responsible research and innovation: epistemic (the complexity and unpredictability of innovations), moral and political (different worldviews and value systems), and power unbalances between stakeholders ([4], p. 31). The authors argue that: 
Given the existing information asymmetries and investment imbalances (...) it is highly questionable whether the presupposed symmetry between moral agents and moral addressees is legitimized. ([4], p. 31)

Despite these asymmetries, the perspectives of lay ethicists are preferred for two main reasons: lay reflections offer stronger and more detailed remarks on how specific technologies can influence everyday life; the inclusion of lay ethicists can increase public trust in science and technology, becoming a strong political reason for their participation [42].

It has been recognized that exercises of public engagement with NESTs and nanotechnologies in particular often repeat the same stories, archetypal narratives, moral dilemmas, visions, and concerns $[13,41,42]$. This can raise some questions not only regarding the "novelty" of nanoethics but also concerning the agency of participants, as their ethical standpoints are determined by past structures/narratives. According to van der Burg, these narratives can inform decision making in more robust ways if lay ethicists reflect on specific questions, use diverse imaginative input, and argue for their standpoints [42].

The narrative and archetypal dimensions of technologies, which can generate a wide range of visions of technological futures, both utopian and dystopian, supported the development of forms of "vision assessment," which have become central after 2009, when we organized the deliberative forum $[23,30]$. Vision assessment is:

an interactive approach that consists of broad consultations with the expected users of the technology and compare them with the visions of the technology developers'. In these exercises, stakeholders are asked to debate standards and criteria of merit of the technology, to discuss problem definitions and possible solutions, to envision the contexts of use of the technology, and describe the "desirable final state". ([30], p. 46)

The deliberative forum that we organized in 2009 was one of the earliest experiences of upstream engagement with nanotechnologies, and the only initiative of the kind ever organized in Portugal. It was as an interesting event to explore how different social groups and stakeholders imagine sociotechnical and nanotechnological futures, allowing us to delve into the relationship between context/format and participatory dynamics. In fact, and supported by regular comparisons with the previously organized focus groups, we argue that the forum was a good illustration of the performativity of deliberative assemblages.

\section{The Deliberative Forum on Nanotechnologies}

The deliberative forum took place at the Centre for Social Studies of the University of Coimbra on March 7, 2009. Seventeen participants, with different backgrounds, gathered for the whole day. The group included participants of the focus groups previously organized within the DEEPEN project [11], scientists involved in nanotechnology research, and members of organizations and associations, such as migrant and development associations, student associations, medical organizations, parents' associations, alternative medicine institutes, movements for free software and for the popularization of science.

Drawing upon previous work carried out within the project, five main matters of concern related to nanotechnologies and, more broadly, to emerging technologies were identified: (a) health and the environment; (b) control, regulation, and public policies; (c) justice, access, and (in)equality; (d) alternative strategies or futures within research (policies); and (e) the political economy of emerging technologies. For this deliberative forum, participants were asked to draw on issues of control, regulation, and public policies and on the political economy of nanotechnologies as entry points into the debate. 


\section{Starting Points}

The deliberative forum started with a plenary session in the morning. A brief presentation of the DEEPEN project and the deliberative forum, including its organization, rules, and aims, was made by a member of the research team. A plenary session followed, where initially participants introduced themselves. Afterwards, the forum continued with the presentation of the two selected topics. This presentation was divided in four parts, featuring respectively two concerned citizens, who participated in the focus groups we carried out previously, as well as two researchers working in the field of nanotechnology, who offered their views as scientists on the topic of health. One of these scientists elaborated on the potential of nanotechnology to develop new cancer therapies:

Since cancer is a disease responsible for a quarter of the mortality rate in developed countries, it was precisely in the field of cancer that nanotechnology rapidly found its space of intervention.

These four presentations included a wide range of themes, which were taken up in two group sessions:

- Military applications of nanotechnologies, including in the field of surveillance

- Health and environmental risks associated with nanotechnologies

- Disparities in regulation and accountability between health (genetic and viral therapies for Parkinson's disease) and industrial domains (engineering applications and materials)

- Ethics and social responsibilities of science and research

- Science communication, regulation, accountability, and citizen participation

- Positive effects of nanoresearch and nanotechnologies on the economic and health domains

Participants were then divided in two separate groups, with the aim of maintaining as much diversity as possible regarding the composition of each group. For each group, a facilitator and observers were assigned. These sessions had two parts: in the morning, participants were asked to draw a list of problems and concerns; after the lunch break, they were asked to discuss possible responses to the problems and concerns they had previously identified.

Group 1 was composed of a representative of an alternative medicine institute; a member of a local action group; two local representatives of a national migrant association; a science communicator; a nanoenactor from the University of Coimbra; the director of a patients' organization; a biology researcher; and a representative of a free software movement association. Members of group 2 included a science communicator; a representative of an African students association; a nanoenactor from the University of Coimbra; a member of a parents' association; a student; the director of the science museum of Coimbra; a Reiki practitioner/homeopath; and a representative of a local action group.

Both groups started by acknowledging the diversity of applications of nanotechnologies and their potential impacts, emphasizing the existence of a range of regulatory procedures and frameworks. The fields of health and medicine were singled out as exemplary instances of adequate modes of control and potentially positive applications, whereas industrial and military developments were regarded as more prone to secrecy and lack of control. The discussion touched upon environmental and health risks related to industrial applications of nanotechnologies such as clothing, construction, and agriculture. Those areas were considered as not being (yet) adequately and properly regulated and thus unlikely to respond in a decent way to uncertainties and emerging problems, such as new types of waste and associated forms of contamination and pollution. As 
the Science Communicator mentioned: "The problem of waste is a greater source of concern for me than manufacture itself."

The first group discussed risks associated with the increasing presence of nanotechnology applications in consumer products. Questions regarding who is entitled to regulate nanotechnologies or the tension between regulatory and accountability imperatives and market rationality led participants to express concerns with conflicts of interest likely to interfere with effective regulation, potentially triggering a lack of public trust in institutional regulatory mechanisms. A debate about the limits and unintended impacts of regulatory and accountability mechanisms based on prohibition opened up a discussion on the economic costs of regulation. As the director of the Science Museum suggested:

Since powerful economic interests are at stake, we are clearly facing a serious problem which requires regulation at the global scale.

The delocalization of industrial production to less regulated contexts, the increase in prices of consumer products, and the possibility of research and development going underground and unregulated were the main topics of that discussion. Concerns with possible obstacles to innovation associated with the economic costs of regulation were raised by a scientist, drawing on examples from pharmaceutical innovation and the reduction of the number of patents of new molecules.

The second group discussed how different areas of research and development could generate diverse problems, whereas the range of possible uses generates variations in the possibilities of control and regulation. A common position was that regulation must be exercised at different scales and for different sectors, but that there are limits to the possibilities of controlling complexity and unintended effects. Again, the unintended effects of restrictive regulation were mentioned, as well as the delocalization of research and development activities to where regulation is weaker. As a representative of a parents' association stated:

We want to control everything. I mean, we can't control everything! It is impossible, we must be aware of that, it is impossible!

Impacts on human health were identified as twofold. Some (mainly regarded as positive) may be direct, as those related to new medical technologies, drugs, and systems of drug delivery. Others may be indirect, such as those associated with additives in food and in other consumer products or new forms of waste and contaminants. The tension between scientific innovation and the application of the precautionary principle [25], as well as between the interests of citizens and the interests of markets, emerged as a topic in relation with regulation.

Both groups agreed on the crucial role of public participation in the regulation of R\&D as well as of consumer products. As put by an environmental activist:

What concerns me is that regulation is differentiated; there are areas where there are more strict systems of regulation and there are others where there is simply no regulation whatsoever!

The need to clarify what is meant by the public - citizens or consumers? - and what is meant by public participation in regulatory and accountability mechanisms led to a discussion on information and the construction of public opinion. How to make scientific research more transparent and available to the public? The central role of the media in the promotion of a more productive science-society dialog was also highlighted. After all, and as a member of a local action group said-"The scientist is a citizen, and as a citizen he will share with others his experience, his success and failures with research". 
Scientists in both groups expressed their concerns about possible obstacles to science innovation due to false or misleading ideas. The suggestion that specific interest groups could be able to manipulate public opinion led to the discussion of who gains and who loses from nanotechnologies. The role of marketing and of pressure groups was emphasized.

Information and the insistence on the need to educate the public on the benefits and the real risks of nanotechnologies in order to avoid manipulation was a strong topic during the discussion of the second group. The need for multiple modes of disseminating information and promoting education was stressed, in order to effectively address publics of different ages, with different work experiences and different degrees of exposure to scientific and technological knowledge. Two possible ways of informing the public were identified - education and civic engagement. The question of language and the need for intelligibility in science communication was stressed as a condition for social dialog and for the empowerment of citizens.

The definition of research priorities led to a heated discussion within the first group. The main questions raised were the following: Who defines these priorities and what are the grounds for their legitimacy? The issues of military research and technology transfer from military research to possible civil applications, and the unequal distribution of benefits and risks across the NorthSouth divide and between rich and poor populations were mentioned but not explored in depth throughout the discussion.

Both groups elaborated a list of concerns and topics summarizing their discussions. While the first group listed a series of recommendations following their discussion, the second group prepared a formal document which was proposed as a basis for the position document coming out of the forum.

\section{Concluding Discussions}

At the end of the day, both groups gathered again. Each group elected one of its members to present a summary of their discussion, including preliminary recommendations. These were then open to general discussion, after which a preliminary draft of recommendations was collectively elaborated. Over the following week, this draft was open to contributions and amendments by participants. A final document with the agreed upon recommendations was then prepared.

\section{The Final Document}

\section{Preamble}

On March 7, 2009, a deliberative forum took place, organized within the project DEEPENDeepening Ethical Engagement and Participation in Emerging Nanotechnologies - at the Centre for Social Studies, University of Coimbra. The following participants were present: Ana Noronha, Ana Raquel Matos, Anabela Santos, António Fortes, Helena Freitas, João Nuno Moreira, José João Lucas, Lanussinga Moisés, Leonel Silva, Luís Pereira de Almeida, Maria Emília Almeida, Miriam Monteiro, Paula Morgado, Paulo Gama Mota, Polybio Silva, Rita Serra, Rui Seabra, Tiago Catela, and Vasco Pinto.

\section{Recommendations}

Emerging technologies are associated with two types of risks. Some of these are transversal, others are specific to different areas of intervention, such as health, food, agriculture, construction, and the military. Some of them are associated with positive aspects: Discovery, Knowledge, Better quality of life, Sustainable development (energy saving and reduction of consumption). 
Taking into account the concerns and problems raised by the debate surrounding emerging nanotechnologies and their implications, the group of citizens suggested the following recommendations:

\section{General Recommendations}

To generate the necessary mechanisms for communication, disclosure of knowledge, interaction, flowing and sharing of experiences between the various scientific areas and civil society.

The involvement of non-specialists must be contemplated at the various steps of research, information, and regulation.

Investment should prioritize research which takes into account sustainable development. Information should be made available on the current state of research and a website should be created to allow the public to have access to updated progress and results stemming from European projects on nanotechnologies.

\section{Information}

Information should include the explanation of what nanotechnologies are, as well as their diversity, in order to avoid unnecessary public resistance to their development. Incentives should be put in place to allow the media to broaden their coverage of questions related to science, technology, and society; training and updating of information for journalists in this field should also be reinforced.

\section{Education}

As far as education is concerned, and in connection with information, public actions should be carried out for the promotion of science in schools, and the topic of nanotechnologies should be introduced to school curricula (both primary and secondary).

New tools must be developed for schools, opening the school to the community.

Different strategies of education and citizenship must be mobilized. The organism in charge of this may be, at the national level, the program "Ciência Viva," as well as science centers and museums.

\section{Regulation and Certification}

The participation of civil society and regulatory measures must be present throughout all steps of nanosciences and nanotechnologies research, possibly through the involvement of laboratories and a reinforced European observatory of nanotechnologies, whose model could be replicated at the national level. There should be the possibility of applying to other domains the procedures of evaluation and regulation developed for the health field, always taking into account the diversity and specificity of nanotechnologies and their life cycle, for instance, applying to the military domain regulatory mechanisms used in other fields.

The certification of products and materials is advised, since people will tend to avoid products which are not certified. A procedure and an agency in charge of certification should be created, in connection with the regulatory processes, and must be developed by public agencies, acknowledging that different levels of risk in diverse areas imply different levels of certification.

The instruments and processes of regulation and certification could be articulated with networks of laboratories; observatories of emerging technologies and nanotechnologies should be created; existing ethics commissions should eventually be reformulated to include emerging issues and concerns; and existing and future platforms for debate on nano should always include civil society representatives. 


\section{Reactions}

By the end of the day, some participants were asked to provide us with some feedback, reactions, and perspectives on the deliberative forum. The organization of the deliberative event was praised by a representative of a students' association, as it opened up the discussion to a wider community:

I think this [the deliberative forum] is a good initiative because it was not just for the scientific community. It was broadened to associations of migrants, students, etc., and that makes us believe that they are thinking about making nanotechnologies useful for society.

The initiative was also praised by the representative of a migrants' association - although some epistemological and experiential asymmetries existed, it was still considered a valuable learning experience:

I enjoyed being with people with such different experiences and knowledge, and I believe that even if we don't have the same level of knowledge on this specific issue of nanotechnologies, we all learned with each other about this theme, about some of the main concerns and issues.

The dynamic and interactive dimensions of the event were highlighted and were contrasted with less "symmetrical" forms of public participation. As put by an educator, who previously participated in the focus groups and also attended the deliberative forum:

These are processes that really invite us to act, because if they were more hierarchical processes, such as conferences, where citizens are in a more passive situation, maybe they wouldn't be so successful. These are participatory processes, where we - even if we don't know other participants - are able to share ideas and knowledge, and that is highly positive, these events are highly participatory.

One of the observers from the Centre for Social Studies also praised the initiative, but suggested that some topics, specific to nanotechnologies, were neglected, which may indicate that most of the discussion revolved around general topics that characterize NESTs, which, we have seen in the "Public Participation, Upstream Engagement and the Challenges of New and Emerging Sciences and Technologies" section, characterizes most of these exercises:

The procedure was interesting because it gave plenty of freedom to participants, but on the other hand perhaps it would have been useful to give more information on the specific discussion that is taking place regarding nanotechnologies, to generate more debate on some topics that were forgotten.

These reactions suggest that the forum was successful, allowing citizens with different backgrounds to share their reactions and perspectives on nanotechnologies, eventually leading to a position document which turned concerns and standpoints into written recommendations. However, the deliberative event contrasted with the focus groups. The role of the following section is to reflect on how the format of the forum (namely the inclusion of nanoenactors and science communications alongside "lay citizens") eventually enacted asymmetries and differences in habilitation, highlighting the performativity of participatory devices and the role played by context/format in the enactment of ethical and social concerns with nano. We also discuss the important role of facilitators in exercises of upstream engagement with NESTs and the difficulties in identifying stakeholders in emerging technologies. 


\section{Discussion}

\section{The Performativity of Participatory Assemblages: the Making of Concerned/Deliberative Citizens}

Our previous experience with focus groups raised the question of the performative character of participatory research procedures. It was through their participation in the focus groups and through the performances associated with them that a range of persons - who had little, if any, knowledge of nanotechnology and no previous articulation of concerns regarding these technologies - were constituted as concerned citizens, with a stake in the research, development, and uses of nanotechnologies [11]. The assemblage itself thus contributed to the performance of these concerned citizens, becoming a mediator that allowed the development of social and ethical concerns, a sort of technology of the self [20]. The question is relevant as well for the deliberative forum. How were participants performed by the forum as deliberative citizens and/or as stakeholders? We may approach this question by drawing on an extension and reworking of some tools developed within STS and, in particular, as part of literature on the construction of a particular type of institution, economic markets, and of a particular type of actor, the individualistic, calculative agent [10].

This approach may be extended to deal with a range of institutions, spaces, and technopolitical assemblages. Participatory procedures and fora are approached, in this way, as forms of active engagement with the world, as a means of knowing and acting upon the world, a form of inquiry in the sense proposed by John Dewey [14], involving some kind of experimentation. The shape taken by this inquiry, however, will vary depending on the specific configuration we are dealing with [10]. Any participatory procedure may be described as an agencement, assemblage, or arrangement, "a combination of heterogeneous elements that have been carefully adjusted to one another" ([7], p. 319). These assemblages or arrangements are "endowed with the capacity of acting in different ways depending on their configuration" ([7], p. 320). The actual workings and the results of this agency will depend on the specific configuration of participation. According to this view, participatory procedures are experiments in the sense that their outcome is contingent on a number of features including the design of the participatory event, the scope and breadth of participation, group composition, the identification of issues and objectives through the very process of deliberation, how the debate was moderated/facilitated, the actual implementation of decisions, and the capacity of citizens and their representatives to monitor and evaluate the process.

Forms of citizen engagement through participatory/deliberative procedures depend on the design and implementation of specific forms of framing both participation/deliberation and the deliberative/participatory citizen, a citizen habilitated [8] with specific skills and capacities. This habilitation depends on the appropriation of specific knowledge resources by citizens and/or by their representatives. Some of the most celebrated participatory/deliberative procedures found in Europe, such as consensus conferences, have developed specific forms of habilitating or educating the participatory citizen. In this case, the constitution of participants as deliberative citizens met with some obstacles, which could not be effectively overcome due to the format and composition of the forum. The encounter of scientists and science educators/communicators with other participants tended to reproduce some asymmetries in terms of the habilitation of participants, which made a difference in their capacity for sustained engagement, argument, and assertiveness. Scientists and science educators/communicators, despite their frequent claims of sharing, as citizens, the concerns of other participants, took up, most of the time, the role of spokespersons for science, often drawing in an explicit way on their authority as experts or as knowledgeable, informed insiders to the world of scientific research. Most of the exchanges, in both plenary sessions and groups, were marked by this asymmetry between those who were in and those who were out of the worlds of science. As we mentioned in the "Public Participation, 
Upstream Engagement and the Challenges of New and Emerging Sciences and Technologies" section, this is one of the limitations of upstream engagement exercises, but it would be utopian to believe that the perfect participatory exercise would suspend power/knowledge [19] hierarchies between participants. In fact, these differences allowed the forum to be enriched by a variety of opinions and standpoints, thus fulfilling the rationale for the deliberative exercise - the diversity of participants did not result necessarily in a "negative asymmetry" but permitted a more comprehensive assessment of the potential everyday life implications of nanotechnologies [42], one of the virtues of lay ethics.

Nevertheless, there were moments where a recognizable interactive deliberative dynamics emerged, namely during the final plenary session, when recommendations were discussed and vigorously argued, and where all participants made contributions and argued for or against proposals. However, we have to agree with Swierstra and Rip [41] when they suggest that the metaphor of the Arena is suitable to describe devices of public engagement with NESTs and technologies in general. In fact, citizens acted and argued as members of situated collectivesscientists, members of environmental groups and of various organizations-and their interventions and utterances were aligned with particular interests and strategies. In that sense, the deliberative forum, as a mediator, interpellated [1] participants in such a way that they responded by drawing on their positionality in order to enact specific recommendations and nanoethics, ultimately reflecting their group identities and aspirations.

Once again, we believe it is fruitful to establish some comparisons with the previously organized focus groups. The focus groups were designed to include only actors who had no commitment, professional, or academic, to nanotechnologies, but who would be able to constitute themselves through participation in collective discussion as citizens concerned with the implications of nanotechnologies. The absence of spokespersons for science allowed participants to engage in a free and creative debate which enabled them to identify concerns and to suggest possible ways of addressing these concerns. Although participants were required to present some kind of performance which would express their concerns and their views of the way ahead, there was no commitment to elaborating and endorsing a common set of recommendations.

The deliberative forum was explicitly designed, in contrast to the focus groups, as a space where scientists and non-scientists could meet and engage in exchanges over the implications of nanotechnologies, and also as a procedure aimed at producing a set of recommendations. Those who had the highest stakes in this exercise, as one observer noticed, were the scientists and science educators/communicators. They were the only participants who were actively engaged with nanotechnologies and who had stakes, in the short term, in the promotion and public support of these technologies. Scientists were encouraged to take up the role of science popularizers and educators, and many of them have acquired skills for public engagement which they effectively put to use whenever they have to engage with different kinds of publics. For most of the other participants, even for those who were most outspoken about their concerns, the implications of nanotechnologies did not appear with the same urgency, and their capacity to act on them was (rightly) perceived to be limited. Nevertheless, both scientists and non-scientists praised the deliberative event and were eager to share their perspectives on the topic, and the fact that representatives of various organizations and associations were present turned the position document into an interesting set of recommendations on nanotechnologies and NESTs in general, reflecting a wide range of social and ethical concerns on the topic. 


\section{Selection of Participants and Group Composition: Who Counts as a Stakeholder or Affected Person/Group?}

One of the key questions we faced was how to select participants to attend the deliberative forum. This is a common problem regarding the organization of public engagement exercises. As Flynn et al. point out,

in undertaking public engagement, a major question arises about whom to engage - the whole population or representative samples, or purposive samples of those most likely to be directly affected? ([17], p. 246)

As we have seen in the "Public Participation, Upstream Engagement and the Challenges of New and Emerging Sciences and Technologies" section, the selection of participants in exercises related to NESTs is, in fact, a complex and difficult operation. There are two key problems here. The first is to define what it means to be affected by NESTs when most of the effects of the latter are located in the future and are likely to be themselves influenced by choices those potentially affected are, at least theoretically, in a position to influence. One of the key aspects of this complexity is how to identify, among all citizens considered as potential participants, those who will eventually be affected by the technologies under discussion. When it comes to new and emerging technologies, as is the case of nanotechnologies, everyone may be regarded as potentially affected.

Established approaches to the constitution of affected groups associate them with the emergence of a collective response to a situation of crisis, and with the ways in which that situation of crisis unfolds [9, 29]. The move from individual to collective action thus implies, paraphrasing Wright Mills' famous dictum, turning personal troubles into public concerns [35]. These tend to emerge where public controversies unfold, with different positions at stake. In the case of new and emerging technologies, a layer of complexity is added: the implications of the developments, applications, and uses of these technologies are, for the most part, not yet out there, meaning that debates are organized around potential future implications and not around already constituted public matters of concern, which also means that public engagement exercises with NESTs usually reproduce the same archetypal narratives, as mentioned in the "Public Participation, Upstream Engagement and the Challenges of New and Emerging Sciences and Technologies" section.

Under these conditions, our option was to select potential carriers of concerns which were likely to be broadly shared by common citizens. As a result, on the one side, we identified engaged citizens associated with groups, organizations, and movements which are already constituted, are endowed with some stability and continuity, and are active on a range of public concerns, from environmental issues to human rights. In addition, we tried to make a distinction between those who already had some intervention in, or interference with, the discussions associated with new and emerging technologies (not necessarily nanotechnologies), namely those groups engaged in social activism, environmental protection, health-related rights, as well as movements of popularization of science, groups working with alternative views of knowledges, therapeutic and body-oriented practices, for instance. Two scientists working in nanotechnology were invited as well.

The selection of participants for this type of event is strictly dependent on the availability of those who are potentially selectable, adding some contingency to the selection process. Although we may have a broad, diverse, and representative list of selected participants, we always depend on their interest/willingness to participate, and their personal views of usefulness and convenience to be part of such an exercise. 
The content and outcomes of this type of exercise are always influenced by the selection constraints and the final composition of the group. In contrast with our focus groups experience, in the deliberative forum lay citizens, nanoenactors and science communicators all shared the same space of discussion. Although lay participants were selected as spokespersons for (potentially) affected groups, only scientists and science communicators could really be described as stakeholders, being in fact the only ones who had an identifiable stake in the exercise and in its short-term effects, which, as previously indicated, also reinforced asymmetries between participants.

\section{The Role of Social Scientists and/as Facilitators}

We did not hire professional facilitators to conduct the deliberative event. The leader of the Portuguese DEEPEN team, a Full Professor in Sociology with a vast experience in the organization of public participation exercises in the fields of science, technology, and health, served as the main facilitator. Another member of the research team, at the time with more than a decade of experience in public engagement with science, facilitated one of the group sessions. Some of the intended roles of the facilitators included moderating the discussion; ensuring that all participants expressed their views on the topic and that no one monopolized the debate; making sure that the discussion was focused on the agreed topics; writing down relevant ideas/topics that were mentioned; keeping up with the schedule (as each group should have an early draft with their recommendations ready to be discussed during the final plenary session).

The facilitation of both the plenary sessions and the groups proved to be a complex task. Throughout the whole forum, in both plenary and group sessions, the balance between allowing discussion to flow freely and trying to redirect voice away from scientists and science educators/communicators to other participants met with the locking in to some topics and directions of discussion, usually in the wake of interventions by scientists. At some moments, the very flow of discussion led to situations which made the facilitator's task even more difficult. Both facilitators (sociologists and members of the research team) were drawn into the discussion by other participants to provide information or even counter-arguments to statements by scientists and science educators/communicators.

This was the case in particular for topics which allowed to bring into the discussion even those participants who were less disposed to engage with topics requiring some familiarity with scientific and technological vocabulary and practices. In some cases, yielding in to these interventions was not an option, and, interestingly, facilitators qua social scientists appeared in a role akin to that of counter-experts, bringing into the discussion information and qualifications of statements made by scientists and science educators/communicators. This raises the intriguing possibility that this recruitment of facilitators into the discussion may be one way of bringing the agonistic dynamics associated with public controversies - and which was familiar to most of the participants as members of civil society organizations or activists - into the procedure, working as a device to support deliberative and interactive dynamics in cases of power/knowledge asymmetries.

\section{Conclusion}

Despite the previously mentioned limitations, the deliberative forum was successful. Citizens with various moral, cultural, and social standpoints, and different levels of expertise, participated in a deliberative arena where various visions of nanotechnological futures were debated, and attempts were made to regulate and control those technological futures through a set of 
recommendations. The position document was a reflection of how participants were interpellated by nano, articulating their concerns through statements that touched upon various fields, such as information, education, regulation, and certification.

As Wilsdon et al. argued [45], upstream engagement is no panacea, and since innovation does not happen in a linear fashion, these deliberative events should be interpreted as opportunities for the involvement of all stakeholders in an ongoing discussion of technological futures. Therefore, the deliberative event should not be assessed on the basis of its binding capacity, resulting in a series of statements that would acquire a quasi-legislative status, obliging nanoenactors to follow certain recommendations. Instead, it should be interpreted as part of an archipelago of deliberative experiments that move public participation away from the old deficit model of science/society couplings and toward novel and innovative forms of engagement.

One can obviously question whether these public engagement exercises are taken seriously by nanoenactors. As Viseu wrote,

Science policy and funding guidelines have come to include calls for integration of the social sciences and humanities in technoscientific research and development projects to maximize societal benefits while minimizing negative impacts and public controversy. ([44], p. 15)

However, during her 3-year experience at the Cornell NanoScale Facility as the in-house social scientist, she felt marginalized, and the asymmetries she systematically experienced illustrate how "integration work" is particularly tricky.

In 2017, the first author of this paper was invited to participate in a round-table at the International Iberian Nanotechnology Laboratory (INL), a Portuguese-Spanish initiative located in Braga, Portugal, and inaugurated in 2009 (some months after the deliberative event took place). This event, organized by the "Knowledge, Science and Technology" group of the Portuguese Sociological Association, included two social scientists and two nanoenactors from the INL.

Each panel speaker delivered a short 5-min presentation and then there was a discussion between all speakers and the audience. The nanoenactors highlighted the "positive" impacts of nanotechnologies, such as nanotherapies for cancer, nanosensors to measure pollution levels, and various other applications, suggesting that there were no significant risks that should be taken into account. Once again, scientists acted like science communicators, presenting an optimistic picture of nanotechnologies, engaging in a sort of technological utopianism that was obviously challenged by social scientists, who fiercely — but unsuccessfully — attempted to remind them that the days of the "deficit model" were over. Moreover, and although various science outreach activities - namely with schools - are often organized by the INL, due to the 2008 financial crisis - that took a severe toll on Iberian economies - there were no funds for the construction of a building dedicated to Science Communication/Public participation, and no exercises of upstream engagement have been systematically organized [18].

This detour serves to highlight that the deliberative forum is, so far, the only deliberative exercise ever organized in Portugal on nanotechnologies. Although the encounter between nanoscientists, lay members of the public, and social scientists was marked by asymmetries that inevitably reflect different visions of nano and technologies in general, the exercise was successful. Once again, some comparisons with the focus groups can underline how the design of participatory devices matters.

The combination of the focus groups model with performance activities allowed participants to bring their concerns and elaborate them in their own terms and in a collaborative way, drawing on their own experiences and skills and building scenarios which, even if informed by access to 
scientific materials, are less constrained by the definitions of what scientists and, more generally, nanoenactors view as the issues. Secondly, as was apparent during the deliberative event, the definitions provided by scientists strongly influenced the direction of the debate. They had a stake in the promotion of a basically positive outlook on nanotechnologies, emphasizing their benefits and circumscribing possible threats and uncertainties to those that could be managed as risks through regulatory frameworks which would not interfere with the need to promote and allow the development of research and development.

As it would be extremely hard to magically suspend asymmetries between nanoenactors and members of the "lay public," social scientists and philosophers should perhaps become mediators in the development of experimental designs for the enactment of speculative nanoethics and nanofutures. This ontological coordination between the visions and aspirations of citizens and stakeholders would require an expansion of the usual methodological repertoire of social scientists, whose "integration work" could be supported by novel technologies of visualization (see for instance The SeeingNano Project) and experimentation with nano (albeit in another field, interesting initiatives have been developed within the Oxford Interdisciplinary Microbiome Project). This can potentially lead to the development of smartphone apps, forms of artistic expression, and various innovative technologies of upstream engagement, islands of ontological experimentation that may perform collaborative visions of nanotechnological futures, reflecting the aspirations of a wide range of social actors.

\section{References}

1. Althusser L (2008) On ideology. Verso, London and New York

2. Arnstein S (1969) A ladder of citizen participation. J Am Inst Plann 35(4):216-224

3. Bellamy R, Lezaun J (2015) Crafting a public for geoengineering. Public Underst Sci 26:1-16. https://doi.org/10.1177/0963662515600965

4. Blok V, Lemmens P (2015) The emerging concept of responsible innovation. Three reasons why it is questionable and calls for a radical transformation of the concept of innovation. In: Van den Hoven J, Koops EJ, Romijn HA, Swierstra TE, Oosterlaken I (eds) Responsible innovation: issues in conceptualization, governance and implementation. Springer, Dordrecht, pp 19-35

5. Boal A (1979) Theatre of the oppressed. Pluto Press, London

6. Burri RV (2009) Coping with uncertainty: assessing nanotechnologies in a citizen panel in Switzerland. Public Underst Sci 18(4):498-511

7. Callon M (2007) What does it mean to say that economics is performative? In: MacKenzie D, Muniesa F, Siu L (eds) Do economists make markets? On the performativity of economics. Princeton University Press, Princeton, pp 311-357

8. Callon M (2008) Economic markets and the rise of interactive agencements: from prosthetic agencies to habilitated agencies. In: Pinch T, Swedberg R (eds) Living in a material world: economic sociology meets science and technology studies. MIT Press, Cambridge, Mass, pp 2956

9. Callon M, Lascoumes P, Barthe Y (2001) Agir dans un monde incertain: essai sur la démocratie technique. Le Seuil, Paris

10. Callon M, Muniesa F (2003) Les marchés économiques comme dispositifs collectifs de calcul. Réseaux 21(122):189-233 
11. Carvalho A, Nunes JA (2013) Technology, methodology and intervention: performing nanoethics in Portugal. NanoEthics 7(2):149-160

12. Davies SR, Kearnes M, Macnaghten P (2010) Nanotechnology and public engagement: a new kind of (social) science? In: Kjolberg KL, Wickson F (eds) Nano meets macro: social perspectives on nanoscale sciences and technologies. Pan Stanford Publishing, Singapore, pp 473-499

13. Davies SR, Macnaghten P (2010) Narratives of mastery and resistance: lay ethics of nanotechnology. NanoEthics 4(2):141-151

14. Dewey J. (1991) Logic: the theory of inquiry - the later works, Vol.12. Southern Illinois University Press, Carbondale, IL

15. Dryzek JS (2000) Deliberative democracy and beyond: liberals, critics, contestations. Oxford University Press, Oxford

16. Fiorino DJ (1990) Citizen participation and environmental risk: a survey of institutional mechanisms. Sci Technol Hum Values 15(2):226-243

17. Flynn R, Bellaby P, Ricci M (2011) The limits of upstream engagement in an emergent technology: lay perceptions of hydrogen energy technologies. In: Devine-Wright $\mathrm{P}$ (ed) Renewable energy and the public: from NIMBY to participation. Earthscan, London, pp 245-259

18. Fonseca PF, Pereira TS (2017) Pesquisa e desenvolvimento responsável? Traduzindo ausências a partir da nanotecnologia em Portugal. Hist Cienc Saude-Manguinhos 24(1):165-185

19. Foucault M (1980) Power/knowledge: selected interviews and other writings, 1972-1977. Pantheon, New York

20. Foucault M (1988) Technologies of the self. In: Martin LH, Gutman H, Hutton PH (eds) Technologies of the self, a seminar with Michel Foucault. The University of Massachusetts Press, Amherst, pp 16-49

21. Freire P (1970) Pedagogy of the oppressed. Continuum, New York

22. Goodin RE (2008) Innovating democracy: democratic theory and practice after the deliberative turn. Oxford University Press, Oxford

23. Grin J, Grunwald A (2000) Vision assessment: shaping technology in 21st century society. Springer, Berlin

24. Hamlett P, Cobb M (2006) Potential solutions to public deliberation problems: structured deliberations and polarization cascades. Policy Studies Journal 34(4):629-648

25. Jonas H (1984) The imperative of responsibility - in search of an ethics for the technological age. The University of Chicago Press, Chicago and London

26. Kearnes M, Wynne B (2007) On nanotechnology and ambivalence: the politics of enthusiasm. NanoEthics 1:131-142

27. Kleinman D, Delborne J, Anderson A (2011) Engaging citizens: the high cost of citizen participation in high technology. Public Underst Sci 20(2):221-240

28. Kyle R, Dodds S (2009) Avoiding empty rhetoric: engaging publics in debates about nanotechnologies. Sci Eng Ethics 15(1):81-96

29. Latour B (2005) Reassembling the social: an introduction to actor-network-theory. Oxford University Press, New York 
30. Lucivero F (2015) Ethical assessments of emerging technologies: appraising the moral plausibility of technological visions (Vol. 15). Springer, London

31. Macnaghten P, Davies SR, Kearnes MB (2015) Understanding public responses to emerging technologies: a narrative approach. J Environ Policy Plan:1-19. https://doi.org/10.1080/1523908X.2015.1053110

32. Macnaghten P, Guivant J (2011) Converging citizens? Nanotechnology and the political imaginary of public engagement in Brazil and the United Kingdom. Public Underst Sci 20(2):207-220

33. Macnaghten P, Kearnes MB, Wynne B (2005) Nanotechnology, governance, and public deliberation: what role for the social sciences? Sci Commun 27:268-291

34. Mejlgaard N (2009) The trajectory of scientific citizenship in Denmark: changing balances between public competence and public participation. Sci Public Policy 36(6):483-496

35. Mills CW (1959) The sociological imagination. Oxford University Press, New York

36. Rowe G, Frewer J (2000) Public participation methods: a framework for evaluation. Sci Technol Hum Values 30(2):3-29

37. Rowe G, Marsh R, Frewer LJ (2004) Evaluation of a deliberative conference. Sci Technol Hum Values 29(1):89-121

38. Rowe G, Marsh R, Frewer LJ (2005) A typology of public engagement mechanisms. Sci Technol Hum Values 30(2):251-290

39. Sciencewise (2016) Quality in public dialogue - a framework for assessing the quality of public dialogue. http://www.sciencewise-erc.org.uk/cms/quality-in-public-dialogue-aframework-for-assessing-the-quality-of-public-dialogue. Accessed 12 Dec 2017

40. Sclove R (1995) Democracy and technology. Guilford, New York

41. Swierstra T, Rip A (2007) Nano-ethics as NEST-ethics: patterns of moral argumentation about new and emerging science and technology. NanoEthics 1(1):3-20

42. van der Burg S (2016) A lay ethics quest for technological futures: about tradition, narrative and decision-making. NanoEthics 10(3):233-244

43. Verbeek PP (2011) Moralizing technology: understanding and designing the morality of things. University of Chicago Press, Chicago

44. Viseu A (2015) Caring for nanotechnology? Being an integrated social scientist. Soc Stud Sci 45(5):642-664

45. Wilsdon J, Wynne B, Stilgoe J (2005) The public value of science. Or how to ensure that science really matters. Demos, London 